(c) American Dairy Science Association, 2004.

\title{
Mild to Moderate Clinical Mastitis: Efficacy of Intramammary Amoxicillin, Frequent Milk-Out, a Combined Intramammary Amoxicillin, and Frequent Milk-Out Treatment Versus No Treatment
}

\author{
J. R. Roberson, ${ }^{1}$ L. D. Warnick, ${ }^{2}$ and G. Moore ${ }^{3}$ \\ ${ }^{1}$ Department of Clinical Sciences, \\ Kansas State University, Manhattan 66506-5606 \\ 2Department of Population Medicine and Diagnostic Sciences, \\ Cornell University, Ithaca, NY 14853 \\ ${ }^{3}$ Route 1 Box 139, Pembroke, VA 24136
}

\begin{abstract}
Study objectives were to determine the efficacy of 4 methods (intramammary amoxicillin, frequent milkout, a combined intramammary amoxicillin and frequent milk-out, and no treatment) of managing mild to moderate clinical mastitis in a university dairy herd. Clinical and microbiological cures, milk production, disease progression, and California Mastitis Tests scores were evaluated. Cows meeting the study criteria were assigned to one of four treatment options based on a systematic randomization scheme (blocked by stage of lactation). Treatments were initiated prior to knowledge of culture results. Cows were observed and evaluated on $\mathrm{d} 1$ to $8,15,22,29$, and 36 . Overall, treatments were not significantly different than controls. However, when efficacy was evaluated by pathogen group, differences were observed. Intramammary amoxicillin appeared to be the most efficacious treatment for environmental streptococci. Frequent milk-out appeared to be detrimental for environmental streptococci. Treatment method appeared to have little effect on Escherichia coli mastitis, as nearly all cases recovered within a short time frame. None of the treatments were satisfactory for cases of Klebsiella mastitis. When obtained in a timely manner, treatment selection for clinical mastitis should be based on culture results.
\end{abstract}

(Key words: clinical mastitis, frequent milk-out, treatment, mastitis cure)

Abbreviation key: $\mathbf{C I}=$ confidence interval, CMT = California Mastitis Test, FMO = frequent milk-out, IMMA = intramammary amoxicillin.

Received July 24, 2003.

Accepted October 20, 2003.

Corresponding author: J. R. Roberson; e-mail: jroberso@vet. k-state.edu.

\section{INTRODUCTION}

Mastitis treatment is the most common cause of antibiotic use in adult dairy cows and the most common cause of illegal antibiotic residues (Guterbock, 1993). Although much research has been conducted in clinical mastitis treatment, a consensus regarding treatment has never been achieved. One reason for the lack of consensus is that truly controlled studies with nontreated controls have not been conducted. Thus, most treatment regimes are anecdotal. Many studies have utilized "positive" controls. The use of positives controls (most often an approved intramammary antibiotic) will usually result in one treatment being better than the other. Although often assumed, there is usually no published evidence that either treatment is better than no treatment. Previous studies suggest that antibiotics may be ineffective in treatment of mastitis (Erskine et al., 1991; Guterbock et al., 1993). Some dairy producers and veterinarians have elected to not use antibiotics in their mastitis treatment protocol (Guterbock, 1993; Ashley, 1994). Ashley (1994) reports no loss of quarters or cows over the $4 \mathrm{yr}$ in which no antibiotics were used to treat all clinical mastitis cases. Yet, this protocol may lead to severe clinical mastitis outbreaks with high bulk tank SCC (Cattell, 1996). Because there are so many agents of mastitis, it is unrealistic to expect a single treatment protocol to be effective for all mastitis cases. Most studies evaluating the efficacy of antibiotics in treatment of clinical mastitis have not had nontreated control cows. Thus, it remains unclear as to whether antibiotic therapy for clinical mastitis is better than no treatment.

Several non-antibiotic methods have been suggested for the treatment of clinical mastitis, such as frequent milk-out (FMO) with and without oxytocin, non-steroid anti-inflammatory drugs, steroids, fluids, hydrotherapy, intramammary infusions of saline, antihistamines, diuretics, hot and cold packing, hypertonic saline infusion, ultrasonic therapy, and other supportive therapy. A popular recommendation for clinical masti- 
Table 1. Criteria used to classify the severity of clinical mastitis. ${ }^{1}$

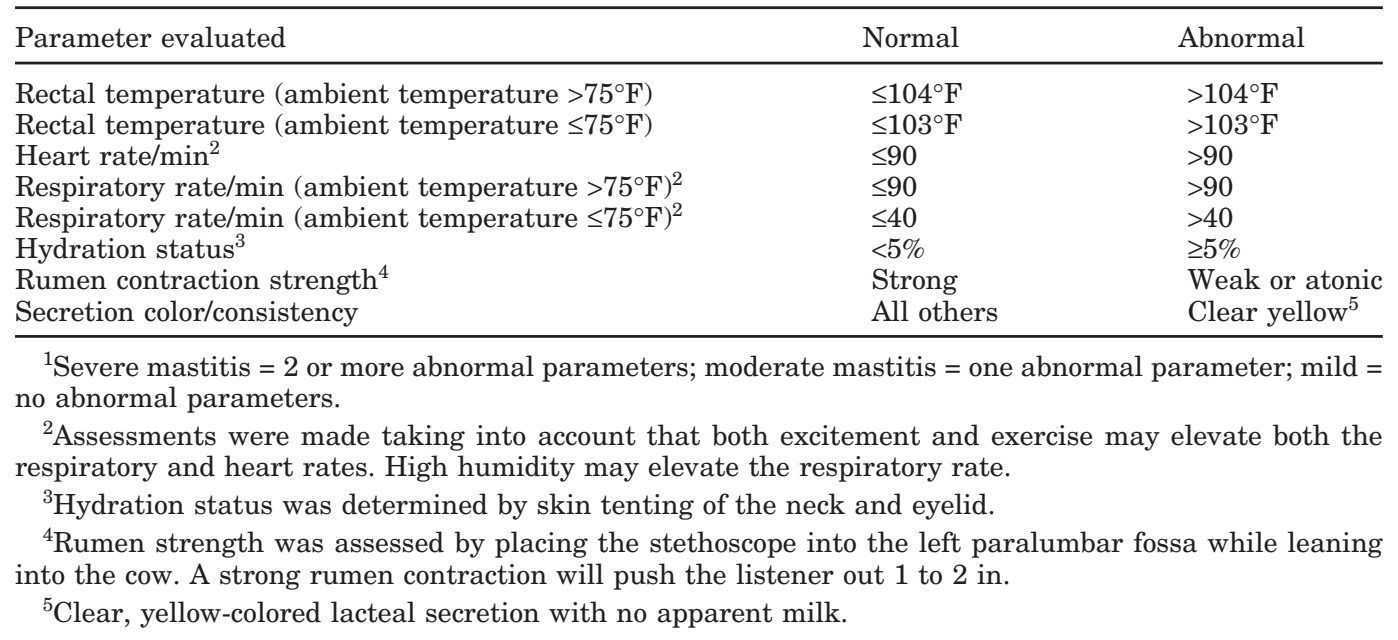

tis is milking the affected quarters out several times a day (Eberhart et al., 1987). In theory, FMO of the affected quarters helps remove the infectious agent and toxic products of the infection. Although there are several studies comparing treatment efficacy between two or more antibiotics, to our knowledge there are only a few studies comparing FMO to any other form of treatment. If FMO is beneficial, then the next step would be to determine the minimum number of FMO that are beneficial, because this method of treatment can be labor intensive and can increase labor costs. A combination of intramammary antibiotic therapy and FMO may be more beneficial than either method alone.

This study is unique, as there is a non-treated control group with which all other groups were compared. This is the first study that compares FMO with antibiotic therapy and untreated controls. The purpose of our study was to determine the efficacy of three methods (intramammary amoxicillin [IMMA], FMO, and FMO + IMMA) for treatment of mild to moderate clinical mastitis and compare them with untreated controls.

\section{MATERIALS AND METHODS}

\section{Study Animals}

The study was conducted over a 2-yr period utilizing lactating Holstein and Jersey cows from a university dairy with prior protocol approval of the University Animal Care Committee. Cows were milked twice a day and housed in freestalls bedded with shavings or straw. Some of the cows were maintained on grass pastures during the summer months. The rolling herd SCC was consistently $<200,000$ cell $\mathrm{s} / \mathrm{mL}$. Pre-milking udder preparation consisted of application of an $0.25 \%$ iodinebased teat disinfection, forestripping, and teat drying with single service paper towels. A $1 \%$ iodine-based teat disinfection was applied post-milking. Milking units were flushed with an automatic backflush system between cows. All cows were treated intramammarily at drying off with cephapirin. No bST or coliform vaccines were being used at the initiation of the study or during the study. Cows with naturally occurring clinical mastitis were detected by dairy personnel during routine milking procedures. Eighty-six percent of cases were in Holsteins, and $14 \%$ were in Jersey cows. A study collaborator examined the cow with clinical mastitis to classify the cow's condition as mild to moderate or severe based on the protocol in Table 1. Cows with clinical mastitis and one or fewer abnormal parameters were classified as having mild to moderate clinical mastitis and were used in the current study. Cows without evidence of clinical mastitis at the time of initial examination were not included in the study. Systemically ill cows with more than one abnormal parameter at the time of initial examination and cows with other concurrent diseases that required treatment were excluded. Cows with clinical mastitis that were included in the study were eligible for a new case of clinical mastitis $36 \mathrm{~d}$ after the previous case, provided that a microbiological cure occurred. If a cow was previously used in the study and a microbiological cure was not obtained, the cow was not eligible for inclusion again unless a different quarter was involved.

\section{Treatments and Method of Treatment Assignment}

Cows that met the criteria were systematically assigned to 1 of 4 treatments after being stratified by stage of lactation. Stage of lactation was categorized as 0 to 90 DIM, 91 to 180 DIM, and $>180$ DIM. Prior to initiation of the study, the 4 treatments were randomly identified as Treatments 1 to 4 . Treatment 1 consisted 
of IMMA (Amoxi-mast; SmithKline-Beecham Animal Health, Exton, PA) administered according to manufacturer's directions (intramammary infusion every $12 \mathrm{~h}$ for a total of 3 treatments). Treatment 2 consisted of no treatment of any kind. Treatment 3 consisted of FMO of the affected quarters at least $2 \mathrm{~h}$ apart during the day for $3 \mathrm{~d}$ in addition to the 2 regular milkings in the parlor for a total of 6 milk-outs per infected quarter per 24-h period. Twenty IU of oxytocin were used intramuscularly to aid each milk-out. Treatment 4 consisted of a combination of Treatments 1 and 3 (FMO + IMMA). Intramammary amoxicillin was given only after the night milking ( 0100 to $0400 \mathrm{~h}$ ) for 3 treatment periods (24-h intervals). Frequent milk-out began at least $8 \mathrm{~h}$ after IMMA therapy following the protocol of Treatment 3. The first cow on the study within a DIM stratum received Treatment 1 . The second cow on the study received Treatment 2 . The third cow on the study received Treatment 3 . The fourth cow on the study received Treatment 4 . The fifth cow on the study, within the same stratum, received Treatment 1 and so forth. All treatments were assigned and initiated prior to knowledge of culture results. If a cow had more than one clinical quarter, all quarters received the same treatment.

\section{Assessment Days and Parameters}

Study cows were assessed prior to milking on $\mathrm{d} 1$ to $8,15,22,29$, and 36 . In addition to the parameters from Table 1 (used to assess progression to systemic illness), the California Mastitis Test (CMT) was scored for each quarter. Milk from the affected quarters was assessed for a clinical cure by stripping milk through a strip cup screen, and a milk sample was aseptically collected from the affected quarters to assess microbiological cure. All teats were dipped with an iodine-based germicide (Blockade; West Agro, Inc., Kansas City, MO) after each assessment and each milk-out.

\section{Cure Definitions and Microbiological Methods}

Outcome variables examined were clinical cure, microbiological cure, progression to systemic illness, CMT scores at d 36, and daily milk production. A clinical cure was defined as no clots or flakes in the milk for 3 consecutive assessment $d$ or 2 consecutive wk without a relapse. A microbiological cure was defined as no growth of the originally isolated pathogen for 3 consecutive assessment $d$ or 2 consecutive wk without a relapse. Clinical and microbiological cures were evaluated on $d$ 7 and 36. Day 7 represented the first day after the end of the withdrawal period for amoxicillin $(60 \mathrm{~h})$ for the FMO + IMMA group. Day 36 was chosen as the end
Table 2. Clinical mastitis culture results by organism.

\begin{tabular}{lrr}
\hline Organism & $\mathrm{n}$ & $\%$ \\
\hline Streptococcus uberis & 30 & 29.1 \\
Escherichia coli & 20 & 19.4 \\
Klebsiella pneumoniae & 15 & 14.6 \\
No growth & 12 & 11.7 \\
CNS & 5 & 4.9 \\
Klebsiella oxytoca & 4 & 3.9 \\
Serratia marcescens & 4 & 3.9 \\
Streptococcus dysgalactiae & 3 & 2.9 \\
Staphylococcus aureus & 3 & 2.9 \\
Yeast & 3 & 2.9 \\
Citrobacter spp. & 1 & 1.0 \\
Enterobacter spp. & 1 & 1.0 \\
Enterococcus spp. & 1 & 1.0 \\
Streptococcus mutans & 1 & 1.0 \\
Total & 103 & 100 \\
\hline
\end{tabular}

point of surveillance for a case. If microbiologic results were negative at the initial sampling and thereafter, then time to microbiological cure was considered $1 \mathrm{~d}$. Fifty microliters of milk were plated on blood agar immediately upon return to the mastitis laboratory, usually within $30 \mathrm{~min}$. Cultures were incubated for 24 to $48 \mathrm{~h}$ at $37^{\circ} \mathrm{C}$. All organisms were initially identified by colony characteristics. Gram-negative organisms were identified by biochemical test strips (API 20E; bioMerieux Vitek, Inc., Hazelwood, MO). Streptococcal organisms were identified by catalase, Gram-stain, esculin, and CAMP reactions. Staphylococcal organisms were differentiated by the tube-coagulase test and hemolytic patterns. Unusual organisms were identified by Gramstain (yeast) or were submitted to the Virginia-Maryland Regional College of Veterinary Medicine Clinical Bacteriology Laboratory. Milk weights were collected at each milking and were used to assess the percentage of decreased production caused by mastitis.

\section{Statistical Analysis}

Descriptive statistics were performed on data by treatment and class of organisms recovered. Data were analyzed using SAS (1990) and EGRET (1993). The effect of treatment group or culture result on dichotomous outcome variables, such as clinical or microbiological cure or new infection, were analyzed at the cow level using logistic regression. For cows with multiple infected quarters, the cow was classified as cured if all affected quarters met the definitions for a clinical or microbiological cure. The effect of treatment on milk production was analyzed using repeated measures ANOVA. Continuous outcome variables (time to clinical cure and time to microbiological cure) were tested for significance using mixed linear models with blocking factors for stage of lactation included as random effects. Quarter data were analyzed using the Fisher Exact 
test $(2 \times 2$ tables $)$ at the Simple Interactive Statistical Analysis website (http://home.clara.net/sisa/).

\section{RESULTS}

\section{Descriptive Statistics}

Eighty-five clinical mastitis events of 70 cows (99 total affected quarters) were eligible for the study. An event was defined as clinical mastitis in one or more quarters at a single point in time. Fifty-seven cows had one mastitis event, 11 cows had 2 events, and 2 cows had 3 events. The minimal interval between consecutive events of clinical mastitis in the same cow was $59 \mathrm{~d}$, and the median interval was $8.5 \mathrm{mo}$. Two-thirds of the repeated events occurred in different lactations. One quarter was affected for 73 of the mastitis cases studied, 2 quarters for 11 cases, and 4 quarters for one case.

The distribution of lactations for cases included in the study was $34 \%$ first lactation, $26 \%$ second lactation, and $40 \%$ in third lactation or greater. Twelve percent of the study events occurred from December to February, $21 \%$ from March to May, 38\% from June to August, and $29 \%$ from September to November. The DIM at the time of diagnosis ranged from 1 to 452 (median $=120)$. None of these factors were significantly different among treatment groups $(P>0.5)$.

Seven percent ( 6 of 85) of mastitis events resulted in a cow becoming systemically ill after entering the study (two Klebsiella pneumoniae, one Escherichia coli, three Streptococcus uberis). Initial treatment of cows progressing to systemic illness was either FMO or IMMA.

\section{Culture Results}

Eighty-five events of clinical mastitis were eligible for treatment comparisons. There were 103 culture results because multiple quarters were infected in some cows, and two pathogens were isolated from 4 of the 99 infected quarters (Table 2).

\section{Treatment Effect on Clinical or Microbiological Cure}

There was no significant effect of treatment on the proportion of mastitis events with a clinical or microbial cure for all organisms combined or stratified by organism category $(P>0.2)$. Clinical and microbiological cures by cow mastitis event are presented in Table 3 . Quarter-level clinical and microbiological cures by mastitis case and major pathogen categories are presented in Tables 4 and 5 .

The greatest effect on clinical or microbiological cures was organism category rather than treatment. Coliform IMI, especially $E$. coli, appeared to be more likely to cure than environmental Streptococci or mixed infec-

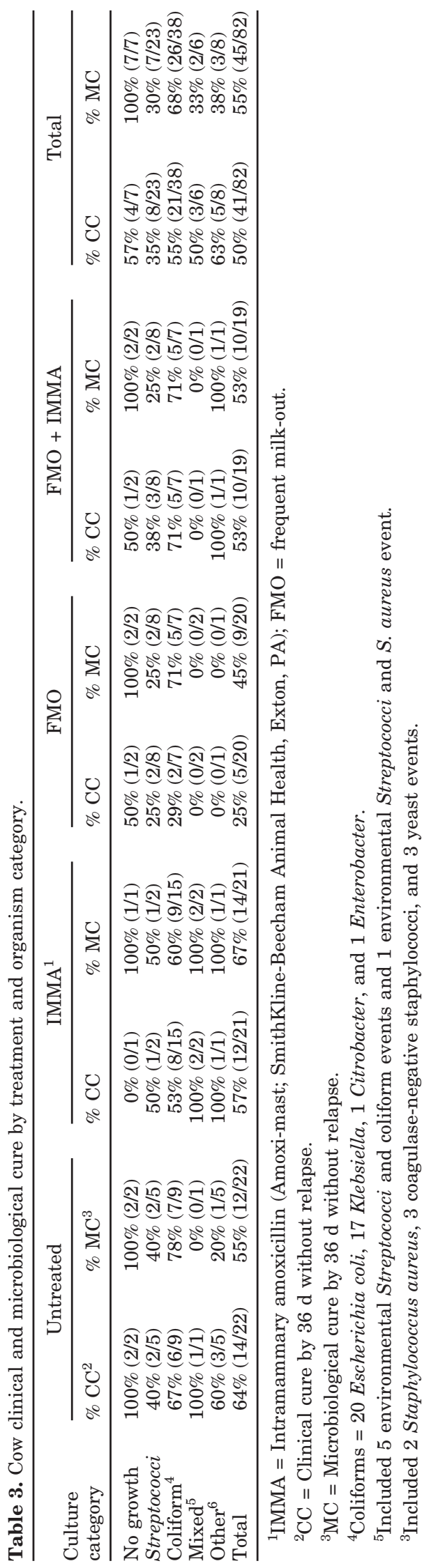


Table 4. Percentage quarter clinical cure within 7 and $36 \mathrm{~d}$ by treatment and organism category.

\begin{tabular}{|c|c|c|c|c|c|c|c|c|c|c|}
\hline & \multicolumn{2}{|c|}{ Untreated } & \multicolumn{2}{|c|}{ IMMA $^{1}$} & \multicolumn{2}{|c|}{ FMO } & \multicolumn{2}{|c|}{ FMO + IMMA } & \multicolumn{2}{|c|}{ Total } \\
\hline No growth & $100(3 / 3)$ & $100(3 / 3)$ & $67(2 / 3)$ & $67(2 / 3)$ & $33(1 / 3)$ & $67(2 / 3)$ & $33(1 / 3)$ & $33(1 / 3)$ & $58(7 / 12)$ & $67(8 / 12)$ \\
\hline Escherichia coli & $100(4 / 4)$ & $100(4 / 4)$ & $67(6 / 9)$ & $100(9 / 9)$ & $67(2 / 3)$ & $67(2 / 3)$ & $33(1 / 3)$ & $100(4 / 4)$ & $68(13 / 19)$ & $95(19 / 20)$ \\
\hline Klebsiella & $20(1 / 5)$ & $40(2 / 5)$ & $0(0 / 7)$ & $0(0 / 6)$ & $0(0 / 2)$ & $0(0 / 1)$ & $50(2 / 4)$ & $50(2 / 4)$ & $17(3 / 18)$ & $25(4 / 16)$ \\
\hline
\end{tabular}

${ }^{1}$ IMMA = Intramammary amoxicillin (Amoxi-mast; SmithKline-Beecham Animal Health, Exton, PA); FMO = frequent milk-out.

tions (all included at least one environmental Streptococci). Logistic regression $P$ values for the effect of organism category, controlling for treatment groups, were 0.01 for microbiological cure and 0.1 for clinical cure.

Microbial growth by quarter for the first $3 \mathrm{~d}$ after treatment initiation is presented in Table 6 , which is divided into no growth, moderate growth (20 to 1700 $\mathrm{cfu} / \mathrm{mL})$, and high growth $(>1700 \mathrm{cfu} / \mathrm{mL})$. Eighty-seven percent of all pathogens had growth within the first $3 \mathrm{~d}$ after antibiotic therapy was initiated. When all pathogens were considered, FMO had a significantly higher percentage of high growth cases than untreated controls and IMMA. For coliforms, FMO had a significantly higher percentage of high growth cases than untreated controls and FMO + IMMA groups. Considering only Streptococci, the IMMA group had a significantly lower percentage of high growth cases than the FMO and FMO + IMMA treatment groups.

\section{CMT}

California mastitis test data are presented for the major pathogen categories (Table 8). When all results were combined, quarters treated with IMMA were significantly more likely to have a CMT score of "trace" (approximately 300,000 cells $/ \mathrm{mL}$ ) by d 36 than the FMO group $(P<0.05)$. The FMO group had the lowest percentage $(21 \%)$ of quarters with a CMT score of "trace" by d 36 of all treatment groups. No significant differences were noted among streptococcal, coliform, or miscellaneous infected quarters $(P>0.10)$. Among quarters in which culture revealed no growth, $100 \%$ of quarters (3 of 3) in the non-treated group were "trace" by d 36 compared with $0 \%$ of quarters ( 0 of 3 ) in the FMO + MMA group $(P<0.10)$.

\section{Treatment Effect on New Infections in Previously Uninfected Quarters}

Treatment tended to increase the risk of developing clinical mastitis in previously unaffected quarters within $4 \mathrm{~d}$ of starting treatment (logistic regression, $\mathrm{P}=0.06$ when controlling for organism category). The FMO + IMMA treatment showed the greatest effect with an odds ratios of 6.4 (95\% confidence interval [CI]; 1.6, 30.6) for developing a new clinical quarter compared with non-treated cases. For IMMA and FMO treatments, the odds ratios for this comparison were $3.6(95 \% \mathrm{CI} ; 0.9,16.8)$ and $2.4(95 \% \mathrm{CI} ; 0.6,11.1)$, respectively.

\section{Milk Production}

There was a significant effect of treatment on milk production following mastitis $(P<0.001)$ (Figure 1 ). Adjusting for breed, lactation, DIM, month of study, and mastitis organism, cows in the untreated group had similar daily milk production before and after the mastitis event (Table 7). Decreases of 2.0 to $3.1 \mathrm{~kg}$ in production between the period before mastitis and 3 post-treatment periods were observed for FMO and IMMA treatment groups. A 1.9-kg drop was calculated for the FMO + IMMA group $30 \mathrm{~d}$ or more after the mastitis event.

Table 5. Percentage quarter microbiological cure within 7 and $36 \mathrm{~d}$ by treatment and organism category.

\begin{tabular}{|c|c|c|c|c|c|c|c|c|c|c|}
\hline & \multicolumn{2}{|c|}{ Untreated } & \multicolumn{2}{|c|}{ IMMA $^{1}$} & \multicolumn{2}{|c|}{ FMO } & \multicolumn{2}{|c|}{ FMI + IMMA } & \multicolumn{2}{|c|}{ Total } \\
\hline & $7 \mathrm{~d}$ & $36 \mathrm{~d}$ & $7 \mathrm{~d}$ & $36 \mathrm{~d}$ & $7 \mathrm{~d}$ & $36 \mathrm{~d}$ & $7 \mathrm{~d}$ & $36 \mathrm{~d}$ & $7 \mathrm{~d}$ & $36 \mathrm{~d}$ \\
\hline Streptococci & $29^{\mathrm{ab}}(2 / 7)$ & $29^{\mathrm{ab}}(2 / 7)$ & $60^{\mathrm{a}}(3 / 5)$ & $75^{\mathrm{ab}}(3 / 4)$ & $8^{\mathrm{b}}(1 / 12)$ & $22^{\mathrm{ab}}(2 / 9)$ & $9^{\mathrm{ab}}(1 / 11)$ & $18^{\mathrm{ab}}(2 / 11)$ & $20(7 / 35)$ & $29(9 / 31)$ \\
\hline Klebsiella & $40(2 / 5)$ & $60(3 / 5)$ & $14(1 / 7)$ & $29(2 / 7)$ & $67(2 / 3)$ & $67(2 / 3)$ & $50(2 / 4)$ & $50(2 / 4)$ & $37(7 / 19)$ & $47(9 / 19)$ \\
\hline
\end{tabular}

${ }^{1}$ IMMA = Intramammary amoxicillin (Amoxi-mast; SmithKline-Beecham Animal Health, Exton, PA); FMO = frequent milk-out.

${ }^{\text {a,b }}$ Subcolumn means within row and day category with different superscripts differ $(P<0.10)$. 


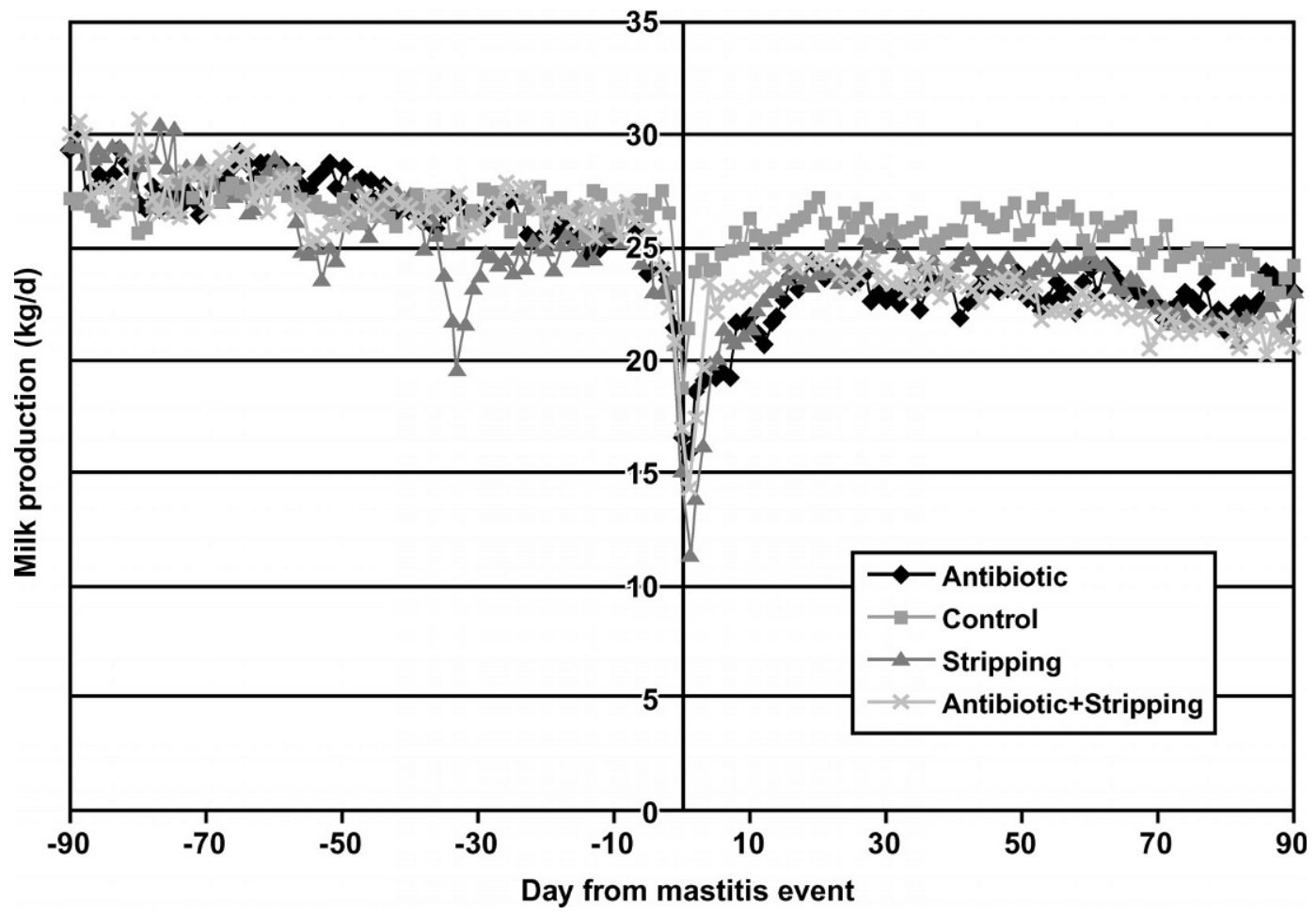

Figure 1. Average milk production relative to the date of mastitis by treatment group. (Note: Data were not adjusted for stage of lactation or season.)

Table 6. Microbial growth during the first $3 \mathrm{~d}$ after treatment initiation.

\begin{tabular}{|c|c|c|c|}
\hline $\begin{array}{l}\text { Culture } \\
\text { category }\end{array}$ & $\begin{array}{l}\text { No growth } \\
\text { after treatment }\end{array}$ & $\begin{array}{l}20 \text { to } 1700 \\
\text { cfu/mL }\end{array}$ & $>700 \mathrm{cfu} / \mathrm{mL}$ \\
\hline \multicolumn{4}{|l|}{ All pathogens ${ }^{1}$} \\
\hline IMMA $^{2}$ & $16 \%(4 / 25)$ & $44 \%(11 / 25)$ & $40 \%{ }^{\mathrm{a}}(10 / 25)$ \\
\hline Untreated & $17 \%(4 / 23)$ & $48 \%(11 / 23)$ & $35 \%^{\mathrm{a}}(8 / 23)$ \\
\hline FMO & $5 \%(1 / 22)$ & $23 \%(5 / 22)$ & $73 \%{ }^{\mathrm{b}}(16 / 22)$ \\
\hline FMO + IMMA & $10 \%(2 / 21)$ & $38 \%(8 / 21)$ & $52 \%^{\mathrm{ab}}(11 / 21)$ \\
\hline Total & $12 \%(11 / 91)$ & $38 \%(35 / 91)$ & $49 \%(45 / 91)$ \\
\hline \multicolumn{4}{|l|}{ Streptococci } \\
\hline IMMA & $40 \%(2 / 5)$ & $40 \%(2 / 5)$ & $20 \%^{\mathrm{a}}(1 / 5)$ \\
\hline Untreated & $29 \%(2 / 7)$ & $14 \%(1 / 7)$ & $57 \%^{\mathrm{ab}}(4 / 7)$ \\
\hline FMO & $8 \%(1 / 12)$ & $8 \%(1 / 12)$ & $83 \%$ b $(10 / 12)$ \\
\hline FMO + IMMA & $9 \%(1 / 11)$ & $9 \%(1 / 11)$ & $82 \%^{\mathrm{b}}(9 / 11)$ \\
\hline Total & $17 \%(6 / 35)$ & $14 \%(5 / 35)$ & $69 \%(24 / 35)$ \\
\hline \multicolumn{4}{|l|}{ Coliforms } \\
\hline IMMA & $13 \%(2 / 16)$ & $50 \%{ }^{\mathrm{ab}}(8 / 16)$ & $38 \%^{\mathrm{ab}}(6 / 16)$ \\
\hline Untreated & $22 \%(2 / 9)$ & $67 \%$ ab $(6 / 9)$ & $11 \%^{\mathrm{b}}(1 / 9)$ \\
\hline FMO & $0 \%(0 / 8)$ & $25 \%^{\mathrm{a}}(2 / 8)$ & $75 \%^{\mathrm{a}}(6 / 8)$ \\
\hline FMO + IMMA & $13 \%(1 / 8)$ & $88 \%{ }^{\mathrm{b}}(7 / 8)$ & $0 \%^{\mathrm{b}}(0 / 8)$ \\
\hline Total & $13 \%(5 / 39)$ & $59 \%(23 / 39)$ & $31 \%(12 / 39)$ \\
\hline
\end{tabular}

${ }^{\mathrm{a}, \mathrm{b}}$ Subcolumn means within column, growth, and pathogen heading with different superscripts differ $(P<0.05)$.

${ }^{1}$ All pathogens excludes quarters yielding no growth.

${ }^{2}$ IMMA = Intramammary amoxicillin (Amoxi-mast; SmithKlineBeecham Animal Health, Exton, PA); FMO = frequent milk-out.

\section{DISCUSSION}

Analyzing the data by genus and species (E. coli and Klebsiella) and major pathogen group (Streptococci) resulted in relatively small numbers per treatment group, thereby decreasing our ability to detect significant differences. However, the researchers felt that potentially relevant information would not be revealed if cases were analyzed as a whole rather than by the methodology used. Findings should not be considered conclusive but rather hypothesis generating for future studies utilizing greater numbers and multiple herds. Direct comparison of results with other clinical mastitis studies is difficult because standard definitions for clinical cure, microbial cure, systemic cure, and total cure have not been established nor has a standard severity scoring system for clinical mastitis been established. In a study by Morin et al. (1998), only 15 of 198 (7.5\%) quarters were still clinical at $14 \mathrm{~d}$ and in a California study (Van Eenennaam et al., 1995); only 24 of 138 (17\%) quarters were still clinical at $4.5 \mathrm{~d}$. In the current study, 28 of $82(34 \%)$ quarters were still clinical at $36 \mathrm{~d}$. This fairly large difference may be related to time of evaluation of the cow or methodology used to determine clinical status. In the Morin et al. study (1998), the cows were 
evaluated within 30 min after milking; in the current study, cows were usually evaluated prior to milking. In the California study, assessment of clinical status was made by udder palpation and visual observation of foremilk stripped on the floor. Further, most studies determine microbial cure based on only one or two followup cultures usually occurring within 4 wk post-mastitis episode. This methodology will result in some falsepositive microbial cures. In addition, prior mastitis literature typically categorizes clinical mastitis as subacute, acute, or peracute (relating to a time frame) rather than by severity level as reported here. Although comparisons are made throughout this discussion, differences may be due to the lack of standards mentioned.

Clinical mastitis etiology was similar to findings of other studies with the exception that the percentage of no growth cultures tended to be lower (Smith et al., 1985; Bartlett et al., 1992; Morin et al., 1998). One reason for the lower percentage of no growth in the current study was probably due to daily culturing of affected quarters, which allowed greater confidence in infection status, even when only a few colony-forming units were present.

\section{Treatment Effect on Clinical and Microbial Cure}

We found no overall or organism-specific treatment effects on clinical or microbial cures when cow was used as the unit. The lack of significance for the analyses of individual pathogens was likely a result of small sample sizes for the analysis of treatment efficacy for specific pathogens. However, the results do suggest that treatment efficacy is different for different organisms when quarter was used as the unit.

Although FMO has been advocated as an accepted means of managing clinical mastitis, the data from this study did not support its use. Morin et al. (1998) demonstrated similar results; in that study, the cows' outcome when treated with antibiotics and FMO and supportive therapy was more favorable than that of cows treated with FMO and supportive therapy alone. The data from the current study suggest that FMO may be detrimental in cases of environmental streptococci. Both FMO and FMO + IMMA groups had fewer clinical and microbial cures than the untreated group. With the possible exception of Klebsiella species, FMO + IMMA did not appear to yield an improved outcome over the other 3 treatments. In a Czechoslovakian study, researchers recommended FMO based on study results of no significant difference between FMO-treated cows vs. those given antibiotics (Opletal et al., 1985). In that study, results were not evaluated by culture result, and cows that did not respond favorably to FMO after $48 \mathrm{~h}$ were included in the antibiotic-treated group. Frequent milk- 
Table 8. California Mastitis Test scores less than "trace" at d 36 by culture result and treatment.

\begin{tabular}{|c|c|c|c|c|c|}
\hline Culture result & $\mathrm{CX}$ & IMMA $^{1}$ & FMO & FMO + IMMA & All treatments \\
\hline Strentococci & $29^{a}(2 / 7)$ & $75^{\mathrm{a}}(3 / 4)$ & $22^{\mathrm{a}}(2 /$ & $27 \mathrm{a}(3 / 11)$ & $22(10 / 21)$ \\
\hline Escherichia coli & $100^{\mathrm{a}}(3 / 3)$ & $89^{\mathrm{a}}(8 / 9)$ & $33^{\mathrm{a}}(1 / 3)$ & $100^{\mathrm{a}}(3 / 3)$ & $83(15 / 18)$ \\
\hline Klebsiella & $20^{\mathrm{a}}(1 / 5)$ & $17^{\mathrm{a}}(1 / 6)$ & $0^{\mathrm{a}}(0 / 1)$ & $50^{\mathrm{a}}(2 / 4)$ & $25(4 / 16)$ \\
\hline No growth & $100^{\mathrm{a}}(3 / 3)$ & $33^{\mathrm{ab}}(1 / 3)$ & $33^{\mathrm{ab}}(1 / 3)$ & $0^{\mathrm{b}}(0 / 3)$ & $42(5 / 12)$ \\
\hline Miscellaneous & $29^{\mathrm{a}}(2 / 7)$ & $25^{\mathrm{a}}(1 / 4)$ & $0^{\mathrm{a}}(0 / 3)$ & $100^{\mathrm{a}}(2 / 2)$ & $31(5 / 16)$ \\
\hline All results ${ }^{2}$ & $44^{\mathrm{ab}}(11 / 25)$ & $54^{\mathrm{a}}(14 / 26)$ & $21^{\mathrm{b}}(4 / 19)$ & $43^{\text {ab }}(10 / 23)$ & $42(39 / 93)$ \\
\hline
\end{tabular}

\footnotetext{
${ }^{\mathrm{a}, \mathrm{b}}$ Subcolumn means within row and treatment category with different superscripts differ $(P<0.10)$.

${ }^{1} \mathrm{IMMA}=$ Intramammary amoxicillin (Amoxi-mast; SmithKline-Beecham Animal Health, Exton, PA); FMO = frequent milk-out.

${ }^{2}$ Seventeen miscellaneous culture results were included in the denominators.
}

out may also increase the time to clinical cure. This theory is partially supported by data in Table 4 in which most culture result categories took longer to achieve clinical cure if FMO or FMO + IMMA were the treatments.

Coliforms. We found that IMMA appeared to have little efficacy against coliform pathogens in that the untreated group had a higher microbial cure than the IMMA group. Such finding is similar to that of Guterbock et al. (1993) in which coliform bacterial cure for amoxicillin-treated quarters was $38.1 \%$ compared with $57.7 \%$ of oxytocin-treated quarters. Cows in the study of Guterbock et al. (1993) study were not frequently milked-out but were simply given oxytocin at the time of routine milking.

The majority of clinical mastitis studies demonstrate a high percentage of microbial cures for $E$. coli (Erskine et al., 1991). The aforementioned statement appears to be true for our study, as treatment appeared to have little benefit for mild to moderate $E$. coli mastitis as the majority of cases cured within 1 wk. In contrast, researchers in a Finland study, in which all cows received intramammary antibiotics, reported only a $71 \%$ bacterial cure for $E$. coli mastitis at 21 d (Pyörälä and Pyörälä, 1998). In the current study, the only cow with $E$. coli mastitis that did not cure bacteriologically by $36 \mathrm{~d}$ had received the IMMA treatment. Morin et al. (1998) stated that their results supported a role for antibiotic use even when most cows with coliform mastitis have only mild disease; however, their data are not presented by severity level nor are the data for the major coliforms (E. coli and Klebsiella) presented separately. In the current study, $85 \%$ (17 of 20 ) of cases of $E$. coli mastitis were cured bacteriologically by $7 \mathrm{~d}$, regardless of treatment. Provided that the cow can be monitored for signs of systemic illness, our data support no treatment as the preferred means of managing mild to moderate $E$. coli mastitis.

None of treatments used in the current study provided satisfactory cure rates for Klebsiella mastitis.
Only a few studies were found that reported a cure rate for Klebsiella. A Wisconsin study reported no cures (0 of 3 ) at $14 \mathrm{~d}$ when treated with intramammary cephapirin (Timms and Schultz, 1984), and a Finland study reported 50\% bacterial cures at 3 wk post-treatment (Pyörälä and Pyörälä, 1998).

Environmental Streptococci. The use of amoxicillin according to label directions resulted in greater microbial cures for Streptococci than the other treatments (Table 5). The data from the current study suggest that IMMA may be important for the management of clinical mastitis caused by environmental Streptococci and that FMO or FMO + IMMA may be detrimental. Intramammary amoxicillin appeared superior to the other treatments, not necessarily because of the $75 \%$ microbial cure $(n=4)$ but more so because of the low cure rates for the other treatments $(29,22$, and $18 \%$ for no treatment, FMO, and FMO + IMMA, respectively). Morin et al. (1998) reported a streptococcal cure rate of $71 \%$ for those receiving antibiotics and supportive therapy vs. only $28 \%$ for those cows receiving supportive therapy alone. Conversely, Guterbock et al. (1993) reported a lower environmental Streptococci bacterial cure of $46.2 \%$ ( 6 of 13) for cows receiving intramammary amoxicillin. Our streptococcal bacterial cure is also consistent with those reported in a recent review (36 to 90\%) of therapy protocols for environmental streptococcal mastitis (Keefe and Leslie, 1997). Although bacterial cure rates of 60 to $80 \%$ would not be considered excellent, they are certainly better than reported cure rates for untreated cases of clinical environmental Streptococci mastitis (29\% in the current study) ranging from 0 to $32 \%$ (Chamings, 1984; Hallberg et al., 1994; Hillerton and Kliem, 2002).

\section{New Clinical Cases in Previously Uninfected Quarters}

We found that treatment did have a significant effect on the development of clinical mastitis in previously 
unaffected quarters within $4 \mathrm{~d}$ of starting treatment. The odds of a new clinical case were 2.4 and 6.4 times higher for cows in the FMO and FMO + IMMA groups compared with non-treated cows. Although oxytocin may not have been necessary for every cow in the FMO group, several cows would not have had a sufficient milk let down without the aid of oxytocin. We observed that when some cows were injected with oxytocin, nonclinical quarters would sometimes leak milk. This might predispose these quarters to new IMI and possibly clinical mastitis. All teats were dipped with a germicide after every FMO, but some non-clinical quarters continued to leak milk. The odds of a new clinical case occurring in cows in the IMMA treatment group were 3.6 times higher compared with that for non-treated cows. Milking out the clinical quarters cannot explain the increased new infections in the IMMA group. None of the cows with new clinical quarters were systemically ill, nor were the new clinical quarters cultured to confirm an IMI.

\section{Microbial Growth During the First $3 \mathrm{~d}$ of Treatment}

Culturing a cow with clinical mastitis after antibiotic therapy has generally been considered a worthless effort. However, the data reported here suggest that culturing after antibiotic therapy may be worthwhile and possibly beneficial in that a decision to change antibiotics can be made more quickly. Clearly, massive growth in the face of antibiotic therapy would suggest the need for a change.

Why FMO treatment did not produce better results is subject to speculation but might be due to the bacteria maintained in a log phase of growth. This theory is supported by the Streptococci data from Table 6 in which both FMO and FMO + IMMA groups were significantly more likely to have high growth $(>80 \%)$ during the first $3 \mathrm{~d}$ of treatment vs. only $20 \%$ of IMMA with high growth. Additionally, the FMO group consistently had the highest percentage of cases with high growth when compared with the other treatment groups for all pathogens.

\section{CMT Scores at $36 \mathrm{~d}$}

Even when a microbial cure occurred, in most cases, CMT scores tended to remain elevated for an extended period of time. Overall, only $42 \%$ of mastitic quarters returned to a CMT score of "trace" by $36 \mathrm{~d}$ with a range of $29 \%$ for Klebsiella to $78 \%$ for E. coli. This is similar to the Wisconsin study of clinical mastitis that reported $40 \%$ of clinical cases returned to a quarter SCC $<400,000$ cells/mL by $14 \mathrm{~d}$ (Timms and Schultz, 1984). With the exception of the no growth category, the FMO- treated quarters consistently resulted in the lowest percentage of cures according to CMT score at $36 \mathrm{~d}$. Combining all culture categories, the IMMA group was significantly more likely to have a CMT cure by $36 \mathrm{~d}$ than the FMO group.

\section{Treatment Response Differences Among Coliforms}

Studies of clinical mastitis therapy typically group all coliforms together. Data from the current study suggest that clinical mastitis caused by E. coli and Klebsiella may respond quite differently to various treatments. Escherichia coli were more likely to respond favorably to any treatment than Klebsiella. Nearly all $E$. coli cases were bacteriologically cured by $7 \mathrm{~d}(85 \%)$ vs. only $37 \%$ of Klebsiella cases. This result was similar to results of Smith et al. (1985), in which clinical and subclinical IMI caused by Klebsiella (34\% cured by 9 d) were of significantly greater duration than $E$. coli IMI (71.2\% cured by 9 d). Separate analyses for different coliform organisms should be considered in future efficacy studies.

\section{Milk Production}

Milk production was almost always lower after a mastitis event, as would be expected, but a difference was noted by treatment. Cows in the untreated group and cows in the FMO + IMMA group tended to have less milk production loss than either the FMO group or the IMMA group. Overall, milk production losses appear similar to those reported by Timms and Schultz (1984). In contrast, Van Eenennaam et al. (1995) showed no significant effect of treatment on 305-d mature equivalent milk production for mild cases of clinical mastitis.

\section{CONCLUSIONS}

Because of the small numbers within compared groups, this single herd study should be considered a pilot study. Although results are suggestive, they are not conclusive. Additional studies in different herds and with greater numbers are required to help verify the results of this study. In evaluating the efficacy of the four different therapeutic regimens for mild to moderate clinical mastitis, none appear superior for all mastitis pathogens. Intramammary amoxicillin may be beneficial for Gram-positive organisms such as Streptococci and coagulase-negative Staphylococci, but its use for Gram-negative organisms and fungal pathogens would seem inappropriate. These findings are in agreement with the results of a recent study in which commercially available antibiotic preparations were considered appropriate for Staphylococcus and Streptococcus isolates 
but were considered ineffective for treatment of coliform mastitis (Bezek, 1998). Although untreated cases were needed for comparison purposes, no treatment may be an appropriate way to manage certain clinical mastitis cases. This was evident from the $E$. coli and the no growth data, in which untreated cases of mastitis cured just as rapidly or more quickly than cases in the other three treatment groups. Because there are no labeled products for fungal mastitis and because fungal mastitis cases tended to cure within $1 \mathrm{mo}$, no treatment would appear to be more appropriate than antibiotic therapy. Frequent milk-out appears to be an ineffective treatment for mild to moderate cases of clinical mastitis. Similarly, combining FMO with IMMA did not appear to improve recovery from clinical mastitis and cannot be recommended based on the data presented here.

\section{ACKNOWLEDGMENTS}

The authors thank the Virginia Tech Dairy Science Department and dairy personnel who cooperated with this research project. The authors also thank the many student workers who assisted with sampling and laboratory work.

\section{REFERENCES}

Ashley, R. 1994. Our non-antibiotic program at the Kellogg Farm. Pages 55-56 in Natl. Mastitis Counc. Reg. Mtg. Proc., Lansing, MI. Natl. Mastitis Counc., Inc., Arlington, VA.

Bartlett, P. C., G. Y. Miller, S. E. Lance, and L. E. Heider. 1992. Clinical mastitis and intramammary infections on Ohio dairy farms. Prev. Vet. Med. 12:59-71.

Bezek, D. M. 1998. Genus identification and antibiotic susceptibility patterns of bacterial isolates from cows with acute mastitis in a practice population. JAVMA 212:404-406.

Cattell, M. B. 1996. An outbreak of Streptococcus uberis as a consequence of adopting a protocol of no antibiotic therapy for clinical mastitis. Pages 123-127 in Proc. Natl. Mastitis Counc. Annu. Mtg., Nashville, TN. Natl. Mastitis Counc., Inc., Madison, WI.

Chamings, R. J. 1984. The effect of not treating mild cases of clinical mastitis in a dairy herd. Vet. Rec. 115:499-500.

Eberhart, R. J., R. J. Harmon, D. E. Jasper, R. P. Natzke, S. C. Nickerson, J. K. Reneau, E. H. Row, K. L. Smith, and S. B.
Spencer. 1987. Current Concepts of Bovine Mastitis. Natl. Mastitis Counc., Arlington, VA.

EGRET Reference Manual. 1993. Statistics and Epidemiology Research Corporation, Seattle, WA.

Erskine, R. J., J. W. Tyler, M. G. Riddell, and R. C. Wilson. 1991. Theory, use, and realities of efficacy and food safety of antimicrobial treatment of acute coliform mastitis. J. AVMA 198:980-984.

Guterbock, W. M. 1993. Oxytocin and other alternatives to antibiotic therapy of clinical mastitis. Pages 67-72 in Proc. Am. Assoc. Bovine Pract., Albuquerque, NM. Am. Assoc. Bovine Pract., Rome, GA.

Guterbock, W. M., A. L. Van Eenennaam, R. J. Anderson, I. A. Gardner, J. S. Cullor, and C. A. Holmberg. 1993. Efficacy of intramammary antibiotic therapy for treatment of clinical mastitis caused by environmental pathogens. J. Dairy Sci. 76:3437-3444.

Hillerton, J. E., and K. E. Kliem. 2002. Effective treatment of Streptococcus uberis clinical mastitis to minimize the use of antibiotics. J. Dairy Sci. 85:1009-1014.

Hallberg, J. W., C. L. Henke, and C. C. Miller. 1994. Intramammary antibiotic therapy: To treat or not to treat? Effects of antibiotic therapy on clinical mastitis. Pages 28-39 in Proc. Natl. Mastitis Counc. Annu. Mtg., Orlando, FL. Natl. Mastitis Counc., Inc., Arlington, VA.

Keefe, G., and K. Leslie. 1997. Therapy protocols for environmental streptococcal mastitis. Page 75 in Proc. Udder Health Management for Environmental Streptococci Symp., Guelph, Ontario, Canada.

Morin, D. E., R. D. Shanks, and G. C. McCoy. 1998. Comparison of antibiotic administration in conjunction with supportive measures versus supportive measures alone for treatment of dairy cows with clinical mastitis. JAVMA 213:676-684.

Opletal, A., D. Ryšánek, and L. SladkÑ. 1985. Therapeutic effects of frequent milking out and antibiotic treatment in acute catarrhal mastitis. Page 414 in Proc. V Int. Symp. Mastitis Control. Bydgoszcz, Poland.

Pyörälä, S. H. K., and E. O. Pyörälä. 1998. Efficacy of parenteral administration of three antimicrobial agents in treatment of clinical mastitis in lactating cows: 487 cases (1989-1995). JAVMA 212:407-412.

SAS. 1990. SAS/STAT User's Guide, Version 6. 4th ed. SAS Inst., Inc., Cary, NC.

Smith, K. L., D. A. Todhunter, and P. S. Schoenberger. 1985. Environmental mastitis: Cause, prevalence, prevention. J. Dairy Sci. 68:1531-1553.

Timms, L. L., and L. H. Schultz. 1984. Mastitis therapy for cows with elevated somatic cell counts or clinical mastitis. J. Dairy Sci. 67:367-371.

Van Eenennaam, A. L., I. A. Gardner, J. Holmes, L. Perani, R. J. Anderson, J. S. Cullor, and W. M. Guterbock. 1995. Financial analysis of alternative treatments for clinical mastitis associated with environmental pathogens. J. Dairy Sci. 78:2086-2095. 